\title{
The artistic Image and characteristics of the Water God in the area along the Ancient Silk Road
}

\author{
FuLi Meng ${ }^{1,2}$, Yu Wang,"* \\ ${ }^{1}$ Shihezi University, School of Literature and Art, Shihe-zi 832003, Xinjiang, China; \\ ${ }^{2}$ No. 225, No. 31 Beishi Road, Shihezi City, Xinjiang, China \\ (e-mail: 1076435664@qq.com; phone: +86-13753103709) \\ *Corresponding author
}

\begin{abstract}
:
With the increasing scarcity of potable freshwater resources around the world, the protection and utilization of water resources in the current ecological civilization society should be more scientific and accurate. It has become the focus of academic research to excavate the wisdom of water use in the daily production and life of ancient society and give full play to its value of the times. This paper attempts to take the image of the water god in folk art as the research object, focusing on the artistic image characteristics of the water god along the ancient Silk Road, under the triple vision of belief, culture, and aesthetics. by using the methods of historical carding, category study and case analysis, this paper mainly combines the three important categories of water god belief places, visual images and folk texts in the oasis settlement in arid areas. This paper makes a point-by-point study of the relationship between
\end{abstract}


this belief proposition and human aesthetic activities and analyzes the artistic characteristics of cross-regional water god worship on the origin and transplantation along the Silk Road. From the aspects of art dissemination, regional resources (humanities and nature), technological exchanges, etc., this paper attempts to reveal the important folk art exchanges in the cultural exchanges between the East and the West under the ancient Silk Road worship art form and spatial distribution, as well as the development value of resources on the current Silk Road cultural belt.

Keywords : The Silk Road, Belief in Water God, Artistic image, Value reuse.

\section{Introduce}

As a necessity for survival and development, water has a profound influence and restriction on human beings. with the deepening of people's understanding of it, water has changed from the "deified" resources worshipped and feared by the ancients to the modern "materialized" development of economic resources, and then to the protection and rational utilization of economic resources under the current ecological background. Because the belief in Water God has a strong regional color, different geographical environments, humanistic atmosphere, and social politics will give birth to different belief contents and expressions. the unique geographical environment and folk cultural atmosphere of the areas along the Silk Road make it very different from other regional cultural circles. As different from the water god belief culture in abundant water resources area, the water god belief culture in the arid area along the Silk Road is not only the product of regional cultural characteristics but also has a certain influence on the exchange of ideas, culture, and folk customs along the Silk Road. The study of the belief in water gods from the perspective of regional culture along the ancient Silk Road is of great value for us to understand the folk culture, belief culture, and artistic aesthetics in the ancient Silk Road.

This study attempts to take the ancient Silk Road as a cultural space and geographical space, 
to study the relationship between folk belief and artistic expression, to explore the regional water culture type research centered on the artistic image of the water god, and to reveal the ecological wisdom in production, life, and spiritual belief through the mutual evidence between written and non-written materials and the value expression of water god belief culture.

\section{Research review}

The research on the belief of water gods along the Silk Road is "very limited at home and abroad". There is less research and exposition on the artistic images of water gods, taking the Silk Road as cultural space, geographical space, water culture and water worship in the origin and transplantation, visual images and text display of the construction of folk culture and artistic image analysis is less. The study of water god belief culture mainly includes the following three aspects:

1. Research institutions. Water god worship is a branch of nature worship in folk culture, and the protection of water resources has been a hot issue in academic circles. Generally speaking, the concept of "water culture" has been integrated into the discourse practice of social production and daily life (Wang 2017;Zhong 2018; PL 2021). The research institutions for the water god belief culture are mainly various universities, such as Wuhan University, Nanjing University, Hehai University, Shanxi University, and so on. They mainly focus on the regional water belief, the regional social research with water as the link, and the water belief research of hydrological science and technology based on history and culture.

2. Belief in Water God and its changes in the process of History. As a kind of folk belief, water god worship has a long history, and the academic circles have studied it for a long time. Mr. Huang Zhigang was the first to study water god. His book "Water God of China" makes a comparative analysis of many myths. Based on ancient books and legends, this paper summarizes, combs, and discusses the situation of water gods in various parts of the country. In his book Water worship in China, Xiang Balisong studied the basis of belief in water gods, the original connotation and development of aquatic mythology and water worship, the 
constituent factors and the objects of water worship, water worship rituals, and the influence of water worship on Chinese culture and history. Wu Bingen (2017) makes an overall study of Chinese folk beliefs in his book Chinese Folk beliefs, in which he briefly expounds on the worship of water and water gods, and introduces the main worship of water gods of each nation.

3. Interdisciplinary belief in Water God and its artistic form.Ethnology. folklore, history, human geography, literature and art, and other different disciplines are involved in the study of water god belief. In Shen Songbai's study of the belief in the Water God of Wu and Yue, the author takes the Wuyue area as the research scope and uses the knowledge of folklore, sociology, and anthropology to theoretically analyze and summarize the belief in Water God from the perspectives of life and folklore, but there is little discussion on the carrier and characteristics of the belief in Water God. In Hu Mengfei's study of Water God belief along the Beijing-Hangzhou Canal in the Ming and Qing dynasties, the author macroscopically grasps the composition and distribution of water god belief in the Beijing-Hangzhou Canal from a historical point of view. this paper analyzes the reasons and conditions for the rise and spread of water god belief in Beijing-Hangzhou Canal from both natural and social aspects, and expounds on the influence of water god belief on the national water control activities in Ming and Qing dynasties and the social life of local people along the coast. In the above article, the biased regional research on the transmission and change of the image is not comprehensive in the systematic and holistic research of the research content.

On the whole, according to the data of water god belief collected by the author, most of the existing discussions are about the description and nature analysis of water god Noumenon and its historical origin, evolution process, cultural connotation, cultural history significance, and rain praying ceremony process. The research on water worship mainly focuses on the connotation, object, regional sacrificial activities, the cultural and historical influence of water worship, while there are few studies on the artistic image and aesthetic analysis, regional art image characteristics, and evolution of water worship. Further research is needed. 


\section{Research methods and data}

Different geographical environments and humanistic atmospheres will give birth to different belief contents. in the historical development process of cultural and economic exchanges, artistic images, as "historical evidence", together with written materials, will become materials for analyzing and corroborating history and culture. and the core of cultural spirit and image aesthetic intention in the belief in Water God are valuable cultures that we need to inherit and learn today. Through the research methods of artistic anthropology, folklore, iconology, and so on, this paper studies how the ancients express water worship through art, embody the thought of heavy water (water worship concept, water control spirit), and give full play to the function of art. It is devoted to revealing the artistic characteristics of the origin and transplantation of cross-regional water worship along the Silk Road (Figure 1) and analyzes the multiple artistic characteristics of the evolution, commonness, and differences of folk culture and artistic images constructed by the concept of water worship in visual images and text display.

Based on local chronicles, archives, documents, and other historical materials, this paper combs the relevant literature in the basic context of Chinese traditional culture and ecology. Through the research materials of agricultural civilization, natural geographical environment, survival purpose, folklore, cultural blending, and so on, from the theoretical level, belief level, aesthetic level, and practical level, this paper summarizes and summarizes the cultural implication, spiritual core, folk customs and unique value orientation contained in the water worship culture. 


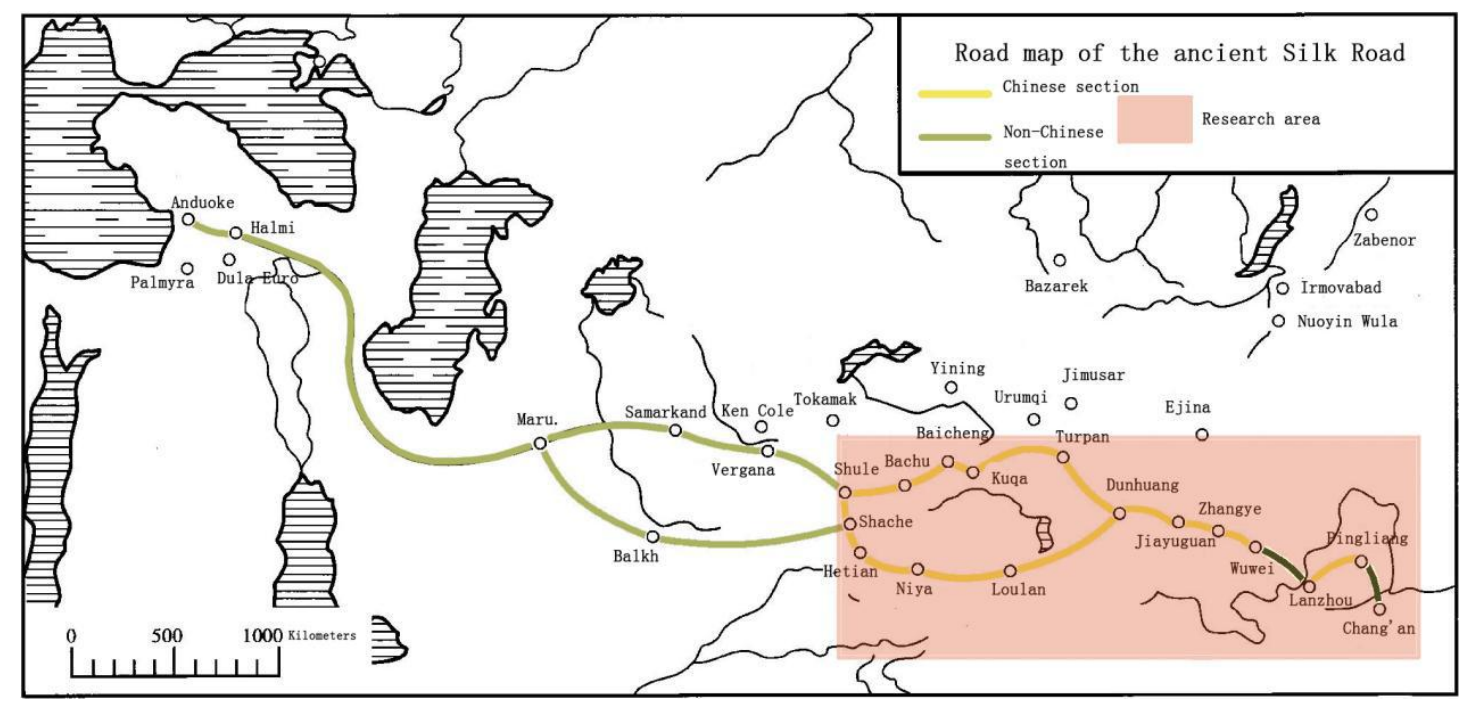

Figure 1 A schematic map of the route of the ancient SilkRoad

Figure source network,Redraw http://www.onegreen.net/jingdianditu/HTML/60920.html

\section{Research results}

\section{The meeting of belief and Aesthetics-- belief in Water God and Folk Art}

Human development and the natural environment are the unity of mutual influence and interaction in the construction of human history. Without exception, the splendid ancient civilization was born and developed from the river basin. The earlier the period of social development, the greater the dependence of human beings on the environment, the lower the level of productivity, and the greater the impact of environmental factors on human beings. The social history along the Silk Road is the collision of nomadic civilization and agricultural civilization. Along the Silk Road, Xinjiang is far away from inland, drought and little rain. The worship of water comes from the important significance of water to life, from the nomads living near the water source to the development of agricultural areas that irrigate water sources, the shortage of water resources will inevitably lead to the contradiction of water use, to maintain stability, the government supports the water god belief and puts the water belief into the national sacrifice, and appropriately regulates the folk water conservancy activities. water belief has become a water belief culture in arid areas, which is different from water-rich areas. Chang'an, the starting point of the Silk Road, is a representative area of agricultural 
civilization, and the climate is more suitable for working people's social agricultural production labor. As the lifeblood of agricultural production and an important factor controlling human survival, water is far more important than other natural objects and has become the earliest and longest object of nature worship.

Folk art is rooted in the ecology of folk culture and studies the relationship between folk art and the spiritual belief of "human". It is the cognition, experience, and psychology formed by people in the process of cognition, development, and survival, as well as the folk cultural ecology based on these cognition, experience, and psychology. The needs of survival belief and life emotion determine the ways and methods of folk art, so the function of folk art not only expresses the feelings of the people but also becomes the symbol of spiritualization of belief worship.

Among the northern nomads in China, the belief in Water God is based on the needs of their living environment, as well as the influence of primitive religion, shamanism, Zoroastrianism, and other ideas of "animism". Shaanxi in the Yellow River basin has relatively superior natural conditions because of the need for farming, the threat of frequent floods and droughts to agricultural production and life, and psychological thirst and fear of water are the reasons for the formation of its belief in water gods. Shaanxi, as one of the birthplaces of China's early civilization, not only farming peoples live here, nomads also produce and live in this area. Under the exchange and collision of various national cultures, the belief in water gods in the areas along the Silk Road is influenced by folk beliefs, traditional cultural thoughts, regional environment, and other comprehensive factors, which is characterized by practicality and utilitarianism. "useful" folk belief culture closely related to production and life.

People have different ways to express the aesthetic ideal of water culture in different periods because it is influenced by the social mode of production, social ideological cognition, social and cultural development, the degree of folk customs, and other factors at that time. The primitive ancestors' cognitive expression of water is mainly totem worship. Nowadays, in the archaeological attern. These are the initial manifestations of the early primitive ancestors' prayers and worship for water, and these objects have become the physical evidence of the early water worship with the combination of practicality and utilitarianism. In the period of 
agricultural society, under the influence of multiple factors, the object of water worship developed from primitive water worship, water-related animal totem worship to water control figures, animal deification, dragons, and other worship objects.

\section{From artistic Image to Folk intention-- the Mutual evidence of Image and words in the belief of Water God}

The areas along the Chinese section of the Silk Road are composed of mountains, basins, Pingchuan, deserts, and the Gobi, and other topography. Water as a necessary factor for the survival of arid areas has derived water-related nature worship such as seeking water and praying for rain. In thousands of years of Chinese cultural history, water belief, as a folk traditional spiritual belief with strong continuity and great influence, is reflected in the images and text materials of the areas along the Silk Road.

The folk culture of water belief appeared as early as the period of primitive Yangshao culture when people had a preliminary understanding of water. Socrates believes that "art imitates nature" and the creation of art is the exertion of imitation instinct. Croce believes that "art is intuition", the source of intuition is emotion, and art is the expression of emotion. Taylor believes that primitive art originates from primitive witchcraft, which is rooted in the animistic worldview. I think the emergence and development of the art of water belief are that the ancient ancestors generated intuition from the cognition of water-based on imitating nature and formed the water belief culture under the idea of animism in practice. The intuitive images of water bodies and animals related to water are drawn into simple, abstract patterns with symbolic connotations in daily necessities, sacrifices, and funerary objects. These early handicrafts not only reflect the primitive ancestors' preliminary understanding of nature but also play a practical function and show aesthetic consciousness to a certain extent. From the grid pattern and fish pattern in the pottery unearthed in Yangshao culture in Shaanxi to the vortex pattern and frog pattern painted pottery unearthed in Majiayao painted pottery cultural relics in Gansu Province, there are also water ripples, fishing net patterns, vortex patterns, and other ancestors' understanding and worship of water in Xinjiang. The appearance of similar patterns in these different regions proves to a certain extent that the development of early human art comes from the understanding and understanding of the world and is related to its 
own needs, and the art image comes from the imitation and abstract generalization of things. it is the imitation of objective things and the processing of subjective emotions.

\subsection{The belief of Water God in the material level}

Chinese traditional farming production mode has a prominent influence on the image of water god belief. The traditional folk season, etiquette, and folklore play different roles in the artistic image in the folk belief system of our country. The area along the Silk Road has always been an area where nomadic civilization and agricultural civilization collide and merge. Gansu in Xinjiang is an oasis agricultural area. Although nomadic agriculture is not developed to a high degree, under the influence of communication with the Central Plains, especially after the Han Dynasty attacked Xiongnu, Jiuquan County, and Dunhuang County were set up. After the Han people migrated to Gansu and other areas, oasis agriculture developed greatly. The picture (Figure 2 ) of farming in the rain in Cave 148 of Mogao Grottoes in Dunhuang is drawn according to the contents of Buddhist scriptures. The painter uses the words "cloud", "rain" and "Gu Miao" in the scripture as the painting content to create a picture of the farmer farming in the rain with the painter's own practical experience of production and life combined with the method of association. In the center of the picture, there is a picture of a farmer and a cow on the left. The farmer is driving the cattle to plow his field in a straw hat. At the top of the picture, there are continuous gray-black dark clouds, the painter expresses the pouring rain with black thin lines, and the picture expresses the farmland in a large area of regular green. The people, cattle, clouds, rain, and fertile land in the painting constitute a picture of the ancient ancestors' desire for Rain Water to bring a good harvest in the rain. In Dunhuang Mogao Grottoes, there is a similar rain picture in Cave 25 of Yulin Grottoes. At the top of the mural, there will be a yellow and black dragon, stepping on red clouds to rain the city. (Figure 3 ) according to literature records, during the period of Emperor Xuanzong of the Tang Dynasty, there was an official ceremony of offering sacrifices to the Dragon King and the Rain Master. It can be inferred that the function of Dragon King Siyu has been established and believed from the folk to the official. 


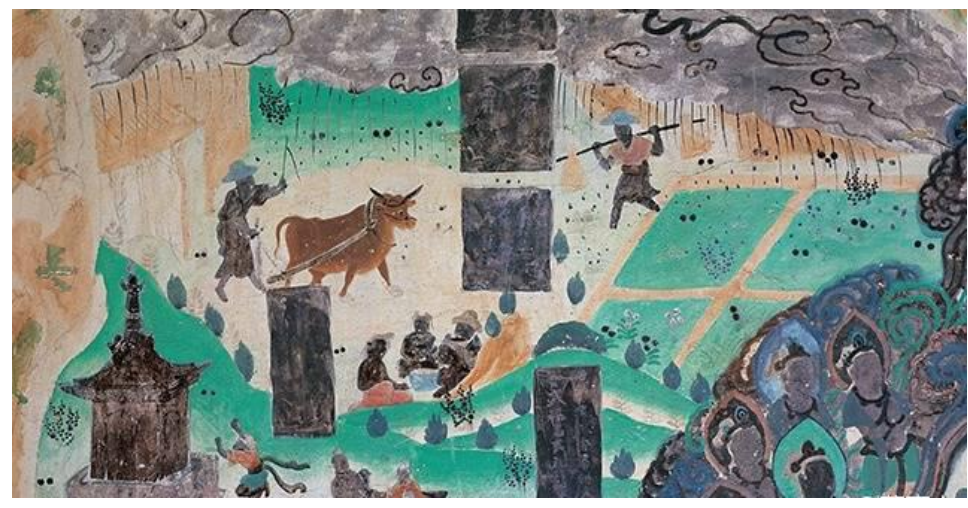

Figure 2 Farming in the Rain Cave 148 of Tumogao Grottoes flourished in the Tang Dynasty Photo from the official Weibo of Dunhuang Grottoes

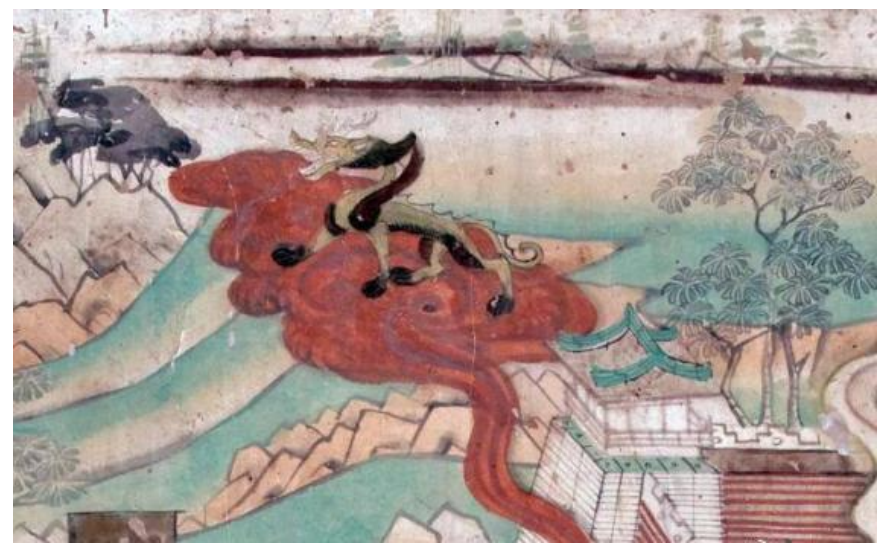

Figure 3 The Middle Tang Dynasty in Cave 25 of Yulin Grottoes Photo from the official Weibo of Dunhuang Grottoes

\subsection{The belief of Water God in the spiritual level}

The artistic image of Water God is an image expression symbol based on symbolic semantics, which is rooted in folk cultural ecology and based on ethnic cultural identity and is a kind of social-cultural consensus. It is a folk art that can interpret the connotation of images under the general psychological structure of the people. The outstanding feature of the art image in the water god belief culture is that it reflects the belief support, ideal needs, emotional comfort, and even psychological dependence of the people. The rain after the drought spread in the network for a long time, meeting friends at home in other places, the wedding day, and the time when the career was successful, these four joyful things cover the career and emotional aspects. only the rainfall after the drought for a long time belongs to both the material and 
spiritual aspects, and it is the spiritual needs extended under the premise of inheriting the material needs of water culture.

The awe, worship and demand of this kind of water can also be seen through some well-known myths, taking the myths and legends of various ethnic groups along the Silk Road as an example, such as the Tatar people in the mythological motif of Qingniuding Earth, under the earth is an endless sea, there is a big fish in the sea, on the beard of the fish stands a calf, and a horn of the calf supports the whole earth. If the green cow is tired, change a horn to support it, and there will be an earthquake. In Kazakh creation mythology, the universe is separated from the darkness and gives birth to a new world; from the boiling mixture, water, earth, sun and stars are produced and the rain-seeking ritual "Tasatek" is recorded. For example, in Uygur mythology, it is obvious that "crops cannot be cultivated because the river is cut off", killing sheep and offering sacrifices to Yahetihan, the god of rain, and so on.

Xinjiang is a multi-religious region. Shamanism, Zoroastrianism, Islam, Buddhism, Taoism and so on all influenced the ancestors of this land. In the data of various gods collected by the famous Finnish Madahan researcher Harry Harun in Xinjiang at the end of the Qing Dynasty, there are 18 categories of temples in Xinjiang, including Buddha statues, Taoist figures, and so on. Among them, there are 20 water ministry gods, such as water official, Mercury, Poseidon king god, Shen Gongxiu sea god, dragon female real person, and so on. Some ancestral temples were built to pray for God to avoid natural disasters. as a result, civil water conservancy disputes continued to emerge. to maintain stability, the Qing government supported the construction of Longwang Temple and appropriately regulated folk water conservancy activities. Longwang Temple is no longer only a sacred place for officials and people to sacrifice but also plays a religious role in the irrigation activities to maintain regional water conservancy order. In this process, its function evolved from "asking for rain" in the mainland to "seeking water" and "dividing water" in Xinjiang (Xian 2019). Xinjiang is oasis agriculture in arid areas. The rationality and utilization of limited and scarce water resources in the allocation of limited resources is a problem that needs to be considered in the planning of social common resources. 


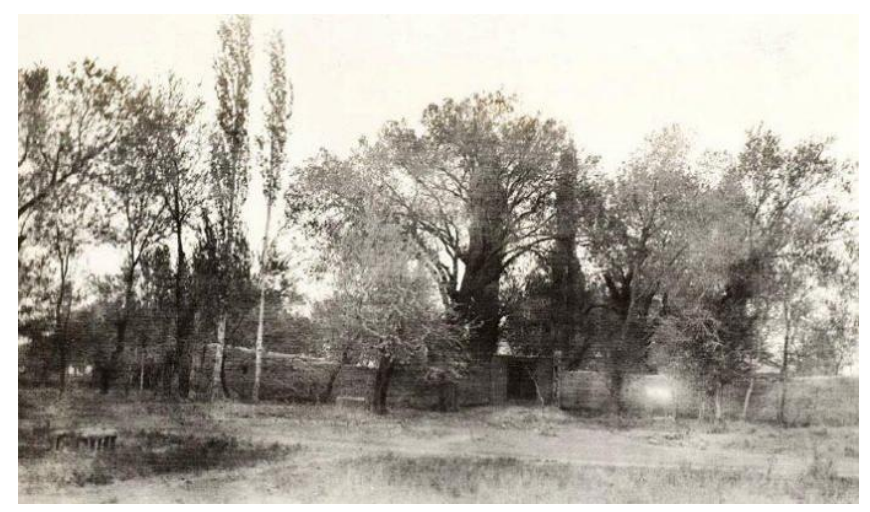

Figure 4 The site of Longwang Temple in Xinjiang

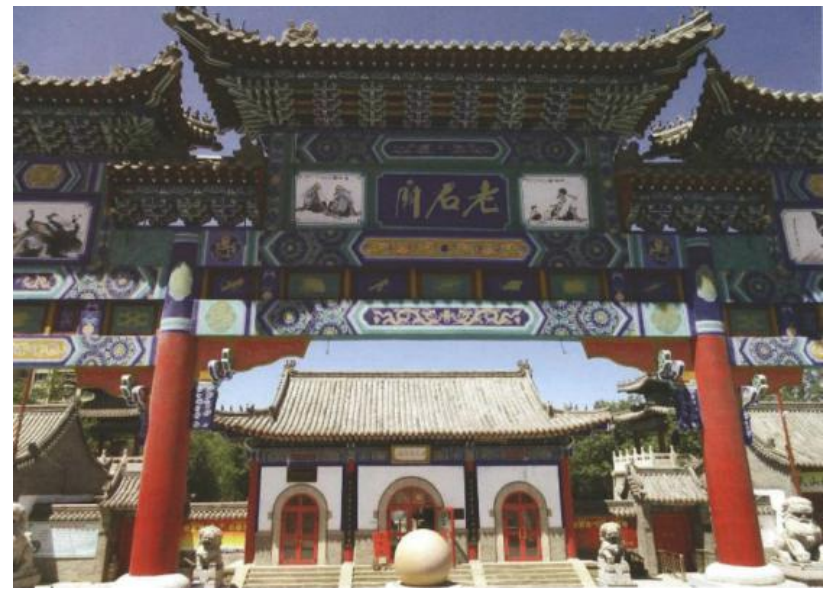

Figure 5 Laojun Temple in Urumqi

\subsection{Belief in Water God at the level of concept}

The profound cultural heritage of the Chinese nation and the dialectical spiritual and cultural thought of the golden mean has exerted an important influence on the spiritual core and formal expression of art. Tao is the highest category of ancient Chinese philosophy. Taoism has Taoism and Confucianism has Confucian Taoism. the Buddhist nature of Zen is also similar to the understanding of Taoism and Taoism. In Chinese traditional philosophy, heaven and man are unified in Tao, which is the way of "unity of man and nature". "the unity of man and nature" is the pursuit of harmony and unity between man and man, man and nature. The thought of "the unity of man and nature" has exerted a great influence on Chinese traditional culture and Chinese traditional art. Unlike Westerners, Chinese people do not completely separate matter from spirit, but integrate spirit and matter, believing that this is the original 
state of the universe, in which spirit plays an absolute role. Because of this, spirituality has become the feature and characteristic of Chinese traditional art. The strong spirit of Chinese art is in sharp contrast to western art.

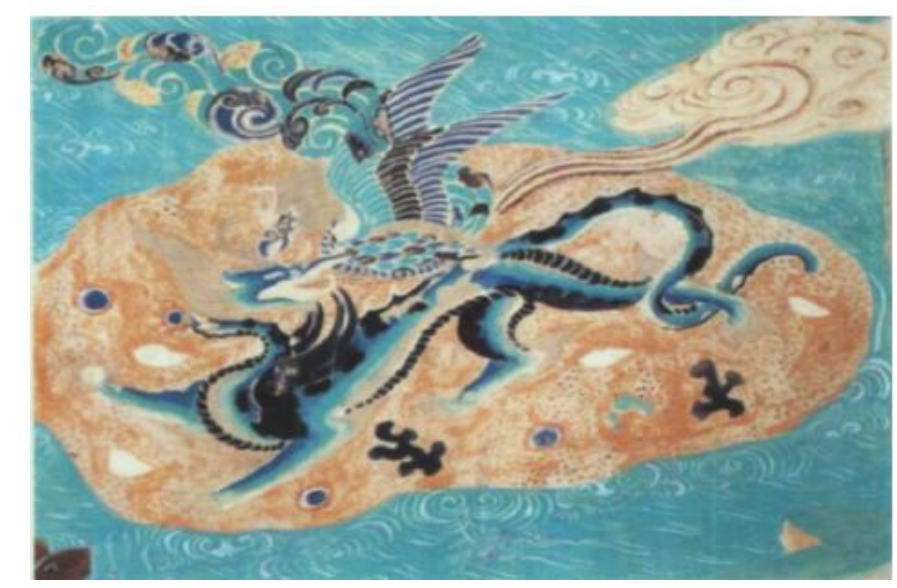

Figure 6 The Water God in Cave 9 of Mogao Grottoes Photo from the official Weibo of Dunhuang

\section{Grottoes}

Chinese traditional aesthetics and Chinese traditional art attach great importance to human subjectivity from the very beginning, thinking that art is the dominant material of psychology, and advocates the unity of psychology and material, in short, the unity of subjective and objective. Therefore, Chinese classical aesthetics and traditional Chinese art have always emphasized the integration of aesthetic subject and object, and have always believed that the beauty of literature and art lies in the integration of emotion and landscape, soul and material, and man and nature, which makes Chinese traditional art have the characteristics of spirit, life, subjectivity, and expression. In the artistic image of the water god, the spiritual connotation of worshiping water is expressed in the image and color of the picture. From the perspective of collecting images, from the image point of view, the expression of water in line, a large area of the dyed intuitive water body; with lines to outline the shape, color, and lines of the animal water god and the Buddhist painting style influenced by the painting style of the water god at that time, such as painters Cao Zhongda and Wu Daozi. From the point of view of the use of color, it is based on the application of the color system under the traditional color view, and most of the images of animal water gods are mainly used in blue (cyan) and black. The first reason is that the intuitive water body is originally similar to blue. Secondly, in the Chinese traditional view of five colors, green has the characteristics of tranquil, far-reaching emotional 
experience, and symbolic meaning. The symbol of cyan is related to its physical characteristics in semantics, but what is more important is the perceptual and emotional factors of human beings. There is an inseparable relationship between green, green and black in our country. In the theory of the five elements, black corresponds to the north, and its patron saint is a kind of tortoise and snake combined animal called Black Tortoise. Tortoise and snake are representative animals in the worship of water gods, which are reflected in their artistic images. The five colors are green, red, yellow, white, and black. The five-color theory is the overall framework of the Chinese traditional color system, which stipulates the relationship between colors that interact with each other, restrict and resolve. (study on the Color of Chinese Folk Art)

As a folk cultural phenomenon, water god belief still exists in the areas along the Silk Road through generations of inheritance and changes. "one of the fundamental reasons is that the folk composition and expression carrier of water god belief itself is rooted in the daily production and life of the people. it forms a part of its development. A complete folk belief should include the subject, object, and expression carrier of the belief. As the creator, inheritor, and disseminator of the folk culture of the water god-belief, the subject of the water god belief participates in the social activities by the way of inheriting, creating, and spreading. In the belief culture, the subject of the water god belief often has additional needs according to their own identity needs in the most basic need for "water". The belief activities of water gods are organized in three ways: non-governmental groups, official organizations, and the interaction between the government and the people. Most of the organizers of folk spontaneous belief activities are mainly local gentry and family prestige, which is different from the belief needs of the general public. Its money and energy in the organization are based on the real purpose of expanding or maintaining its prestige based on praying for "water" resources. The feudal official sacrifice policy also promoted the development of the belief in water gods along the Silk Road.

In terms of images and texts, the worship of water gods along the Silk Road has confirmed that under the influence of animistic concepts such as nature worship and religious worship, under the influence of the ancestors along the Silk Road, under the official auspices and the 
spontaneous sacrifice of the people, the combination of official rituals and folk sacrifices has been formed, which reflects that the worship of water gods acts as a cultural product of connecting the spiritual needs of "man-god" as a communication carrier in the cultural belief system of the ancestors. And as for maintenance of social stability, in the social water resources issues around the management of water, water use, water distribution of water conservancy issues to play a role in maintaining order, the formation of official and folk up and down, the belief of the whole people of an important belief culture.

\section{The Unity of knowledge and practice in response to the Times-- the value expression of the belief concept of Water God in the present}

In the historical process of development, the ancient ancestors along the Silk Road took the opening of the Silk Road as an opportunity, the interweaving of nomadic farming civilization as a link, and the needs of the development of oasis agriculture and animal husbandry in arid areas. it created a regional water culture, which not only represented the development level of productive forces at that time, but also adapted to the external living environment. Including climate, temperature difference, topography, natural disasters and so on. This kind of pioneering, enterprising and adaptability in the face of nature and poor living conditions is the content that we need to inherit and learn when our current social living conditions are superior.

\subsection{Construction of social order}

Generally speaking, the pursuit of "harmony" in the water god belief culture is the realm of "harmony". In Confucianism, there is more emphasis on the harmony between man and society and the unity of emotion and etiquette; in Taoism, there is more emphasis on the harmony between man and nature and the unity of spirit and material; in Zen Buddhism, there is more emphasis on the harmony between man and his ideas, and the pursuit of peace of mind. The belief in Water God not only pursues the harmony between man and nature but also runs through the harmony between man and people, man and society. Such harmony exists from individual to society, from humanities to art, from heaven and earth to the whole universe. In other words, the environment, people, and culture are all harmonious. The harmonious beauty of the unity of man and nature is the highest pursuit of Chinese traditional 
art. Chinese aesthetics requires the unity of beauty and goodness, and although Confucianism and Taoism have different views on the highest realm of goodness, in the end, they all regard "the unity of man and nature" as the highest realm, and the so-called "unity of man and nature" is also a kind of aesthetic realm, a realm of the unity of truth, goodness, and beauty.

\subsection{Ecological protection value}

At present, the construction of ecological civilization has been brought into the overall layout of the cause of socialism with Chinese characteristics, and it is an inevitable requirement to promote the promotion of public ecological awareness. Judging from the content reflected in the culture of belief in God in Sheung Shui, the folk culture that has been worshiping and protecting water for thousands of years has continued to develop, and the pace of the times has not stopped. in today's economic development, social development, and scientific and technological development, the protection consciousness has become relatively thin, and the ancient people already have the concept of ecological environment consciousness is still the cultural treasure that we need to take its essence today. In the formulation of relevant environmental laws and regulations, we should attach importance to water resources from the perspective of moral and emotional constraints to carry out the concept of living in harmony with nature, give full play to the role of art in traditional folk cultures such as festivals and folk customs, enhance the sense of confidence and identity of national culture and culture, further attach importance to the ecological quality education of the people, and strive to build a cultural atmosphere of awareness of environmental protection. Enhance the environmental protection awareness of the public, especially students. Strengthen the improvement and development of the environmental education system.

\subsection{Aesthetic value of art}

Many categories of Chinese traditional aesthetics and art appear in the form of unity of opposites, such as "strength and weakness", "action and stillness", "appearance and connotation", "emotion and rationality", and so on. More in the unity of contradictions in the dominant position. In the artistic images of the belief in water gods, this relationship, which is dominated by the expression of spirituality, provides a reference and guidance for the development and aesthetics of our art today. It is this dialectical thinking that shines with the 
rational wisdom of the Chinese nation, which has a great influence on Chinese traditional art and aesthetic thought, and forms the dialectical harmony view full of national characteristics in Chinese traditional art and aesthetic thought.

\section{Summary and discussion}

In the context of the ecological era, "water", as an indispensable natural resource of life, has become an important object of our research, protection, and utilization. We inherit the past and the future from the water belief culture, and what we want to take from its essence and discard its dross is to integrate the new needs into the present era scene. Inherit the belief of respect for water, the protection and utilization of water, with the concept of ecological, green, and sustainable development.

The ancient ancestors could not control the amount of water and used the method of sacrifice to please the gods in charge of water. The space places, image texts, and behavior rituals of its sacrifice together form the belief culture of water gods. Its sacrificial activities are inseparable from "etiquette and music civilization". The order and etiquette formed in the sacrificial activities of this belief have become the moral laws that restrict the behavior. In the sacrifice to the water god, the rights, obligations, and daily norms of conduct of the members of the society are stipulated. After receiving the grace, the ancestors will be grateful, restrain their behavior, and internalize their beliefs into moral laws that people consciously abide by.

Nowadays, with the rapid development of the economy and society, the belief in Water God seems to have become a lost folk belief. But behind the rapid social development is the pollution and abuse of water resources. In the "regional social relations system with water conservancy as the center", the maintenance of water conservancy order, protection, and rational use of water resources should not be based on the destruction of natural resources. The relationship between man and water has a profound impact on the past, the present, and will continue to shape the future. Nowadays, the widespread problems of water shortage, water environment pollution, and flood disasters in the world affect the long-term and effective utilization of water resources and the realization of sustainable development of human society. We should pick up "water worship" and even "nature worship" again, not to worship the unknown gods, but to be in awe of nature and restrain ourselves from our 
behavior. To establish the natural moral restraint norms at the social level of the masses, respond to the national call that "green water and green mountains are golden mountains and silver mountains", and adhere to the harmonious symbiosis between man and nature. Establishing and practice green water and green mountains is the concept of Jinshan and Yinshan, and adhere to the basic national policy of saving resources and protecting the environment.

\section{ACKNOWLEDGMENT}

This study benefited from the opinions of the reviewers and editors of the journal, and was supported by the National Social Science Foundation of China : "Study on the Cooperative Mechanism of Water Cultural Heritage Protection and Rural Revitalization in Xinjiang Section of the Silk Road"(19XMZ046).At the same time, it is also supported by the State Ethnic Affairs Commission: research on the protection and development of cultural resources in the ethnic minority regiment (town) of the Southern Xinjiang bingtuan.

\section{REFERENCES}

[1] Mao Ning. 2017The discovery and integration of the art ideal of going to the Folk and the folk tradition (1919-1945). China Academy of Fine Arts,

[2] Liu Yan.A study on the Color of Chinese Folk Art . Shandong University, 2016.

[3] Wu Yuhang, Li Fulun. Change and cohesion: water beliefs and legends and their social functions in Dali Erhai Basin. Journal of Honghe University, 2021, 19 (02): 58-63.

[4] Sun Dawei. Complete works of Western Art. 4. Arts and crafts volume. Tianjin people's Art Publishing House, 2016.6

[5] Xianchenghai. A study on the belief of Longwang Temple in Xinjiang in Qing Dynasty. Chinese Culture Forum, 2019 (02): 12713559.

[6] Hu Mengfei. A study on the belief in Water Gods along the Beijing-Hangzhou Canal in the Ming and Qing dynasties . Nanjing University, 2015.

[7] Tang Fei. A study on the Custom characteristics in the murals of the Water Temple in 
Guangsheng Temple, Shanxi. North China University of Technology, 2016.

[8] Cai Honghua. A study on the worship of Water God in the pre-Qin, Qin and Han dynasties . Guangxi normal University, 2013

[9] Yu Ying. Village folklore Folk Art . Central Academy of Fine Arts, 2010.

[10] Wu Yuhang, Li Fulun. Change and cohesion: water beliefs and legends and their social functions in Dali Erhai Basin . Journal of Honghe University, 2021, 19 (02): 58-63.

[11] Lu Yanzhao,Chen Meng,Xue Jinli. Water Culture in the Development of National Cultural Tourism under the New Ecological Environment. Journal of Coastal Research,2020,104(sp1).

[12] 최충익,김철민. Big Data-Based Approach for Regional Water Culture. Journal of Social Science, $2019,58(2)$.

[13] Yuanlei, Zhang Xinlian, Xue Zhiyang, Jiang Xu. The influence of the change of Minority Water Culture on Water Environment pollution-- A case study of Miaolan Village in Southeast Guizhou Province . Rural economy and Science and Technology, 2021, 32 (07): $30-32$.

[14] Zhang Hongyun. Form, symbol and situation: a study on the interpretation Model of Visual Art based on Art History . Journal of Qiqihar University (philosophy and Social Sciences Edition), 2021 (02): 23-27

[15] Wang Shengze. The imprint of Silk Road in Xixia Art Image . Xixia Studies, 2017 (04): $50-57$. 